\title{
The Significance of Neutrophil-Lymphocyte Ratio and Mean Corpuscular Volume in Diagnosis of Preeclampsia
}

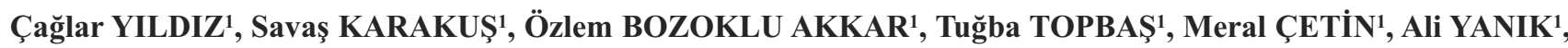 \\ Ali ÇETIN ${ }^{1}$
}

Sivas, Turkey

\section{ABSTRACT}

OBJECTIVE: The aim of this study is to evaluate the diagnostic values of neutrophil to lymphocyte ratio (NLR) and mean corpuscular volume (MCV) in patients with preeclampsia.

STUDY DESIGN: A retrospective analysis of patients with documented preeclampsia and uncomplicated pregnancy was carried out. Two hundred and twelve women with preeclampsia, and 58 healthy pregnant women as controls were included in the study. NLR and MCV values were calculated from complete blood count analysis.

RESULTS: White blood cell, NLR and MCV values were higher in the preeclamptic patients than those of the controls. The study groups had similar features with regard to the maternal age, gravidity, parity, and mode of delivery. Gestational age, newborn weight, and Apgar scores of the newborns were found lower in the preeclampsia group.

CONCLUSION: NLR may be helpful in the differential diagnosis of preeclampsia. Large-scale prospective studies with categorized study groups according to the severity of preeclampsia need to be performed to determine the optimal NLR values useful for the assessment of severity of preeclampsia.

Keywords: Preeclampsia, Neutrophil to lymphocyte ratio, Mean corpuscular volume

Gynecol Obstet Reprod Med 2016;22(2):75-79 DOI: 10.21613/GORM.2016.84

\section{Introduction}

Preeclampsia is a systemic disease described as the new onset of hypertension plus either proteinuria or end-organ dysfunction after 20 weeks of gestation (1). Preeclampsia is estimated to occur in $4.6 \%$ of pregnancies worldwide (2), and about $10 \%$ of direct maternal deaths are associated with preeclampsia and eclampsia (3). Regarding the pathophysiology of preeclampsia, there are many theories highlighting its multifactorial basis. It is probably related to both placental and maternal factors including abnormal placentation, systemic endothelial dysfunction or cell activation, and an angiogenic imbalance favoring anti-angiogenic factors (4). Physiologic anemia, neutrophilia, mild thrombocytopenia, increased procoagulant factors, and diminished fibrinolysis are considered normal during pregnancy (5). It has been hypothesized that circulating syncytiotrophoblast debris contributes to maternal inflammation and some of the features of the maternal syndrome (6). Signs of maternal inflammation encountered in

\footnotetext{
${ }^{1}$ Department of Obstetrics and Gynecology Cumhuriyet University School of Medicine, Sivas

Address of Correspondence: Çă̆lar Yıldız

Department of Obstetrics and Gynecology Cumhuriyet University School of Medicine Sivas, Turkey dr_caglaryildiz@yahoo.com.tr

Submitted for Publication:

21. 04.2016

Accepted for Publication:

27. 04.2016
}

term normal pregnancies are increased in preeclampsia. Preeclampsia is characterized by exaggerated proinflammatory trophoblastic debris and microparticles which are spread during normal pregnancies (7).

It has been demonstrated that leukocyte activation is a major pioneer in the pathogenesis of preeclampsia (8). In addition, neutrophil activation is considered to be a major part of increased inflammatory response in maternal vascular system during preeclampsia (9). Leukocytosis is a finding expected in normal pregnancy (8). However, information related to leukocyte count and its differentials is limited in patients with preeclampsia. Based on these conflicting data, the current study was conducted in order to compare neutrophil to lymphocyte ratio (NLR) and mean corpuscular volume (MCV) values in pregnant women with and without preeclampsia. We hypothesized that preeclampsia increases NLR and MCV values.

\section{Material and Method}

After the approval of the study protocol by the Human Research Ethics Committee of our university, a retrospective analysis was carried out for patients with documented preeclampsia who were admitted to our hospital from January 2008 to December 2014. Preeclampsia was diagnosed as described in the International Society for the Study of Hypertension in Pregnancy classification (diastolic blood pressure $>110 \mathrm{mmHg}$ on single measurement, or $>90 \mathrm{mmHg}$ 
on repeated measures; and proteinuria of $\geq 0.3 \mathrm{~g} / 24 \mathrm{~h}$, or $\geq 1+$ proteinuria on dipstick testing on repeated measures, in the second half of pregnancy) (10). Exclusion criteria included the presence of fetal anomalies and maternal or fetal infection, pregestational or gestational diabetes mellitus, cardiovascular disease, and renal or liver diseases. Two hundred and twelve women with preeclampsia, and 58 healthy pregnant women as controls were included in the study. The clinical and ultrasonographic data of the women with preeclampsia and controls with an uncomplicated course of pregnancy were obtained. Maternal age, gravidity, parity, gestational age, mode of delivery, newborn weight, Apgar score, systolic and diastolic blood pressure, proteinuria, and hematological values were collected.

\section{Statistical analysis}

Data were presented as mean \pm standard deviation (SD), median (minimum-maximum), or percentage as appropriate. The maternal age, gravidity, parity, gestational age, mode of delivery, newborn weight, Apgar scores, systolic and diastolic blood pressure measures, and the proteinuria levels were compared with t test. The WBCs, neutrophil, lymphocyte and platelet counts, and the hemoglobin levels were analyzed with Mann-Whitney U test. Significance was determined at the $\mathrm{p}<0.05$ level.

\section{Results}

The clinical, demographical, and hematological characteristics of the study and control groups were analyzed. Table 1 presents demographic and clinical data of the study groups. There were no significant differences between the study groups regarding the maternal age, gravidity, parity, and mode of delivery $(\mathrm{p}>0.05)$. However, gestational age, newborn weight, and Apgar scores of newborns of the patients with preeclampsia were significantly lower than those of newborns of the patients with uncomplicated pregnancy $(\mathrm{p}<0.05)$. Systolic and diastolic blood pressure values and proteinuria levels were significantly higher in the preeclamptic patients $(\mathrm{p}<0.05)$.

Selected hematological parameters of the study groups are shown in Table 2. The neutrophil and lymphocyte counts of the preeclampsia group were significantly lower than those of the control group; however, the WBCs count of the preeclampsia group was significantly higher than that of the control group $(p<0.05)$. The hemoglobin level and platelet count of the study groups were comparable $(p>0.05)$. The NLR and MCV of the preeclampsia and control groups are presented in Figure 1. The median NLR value of the preeclampsia group was significantly higher than that of the control group [4.7 (1.2-12.0) vs. $3.9(2-6.2) ; \mathrm{p}<0.05]$. The preeclampsia group also had a significantly higher value of MCV compared to the control group ( $85.9 \pm 5.9$ vs. $90.8 \pm 5.8$; $\mathrm{p}<0.05)$. In the preeclampsia group, there was no significant correlation between the NLR and MCV values ( $p>0.05)$.

Table 1: Selected demographic and clinical data of study groups

\begin{tabular}{|c|c|c|}
\hline & $\begin{array}{l}\text { Controls } \\
(n=58)\end{array}$ & $\begin{array}{l}\text { Preeclampsia } \\
(n=212)\end{array}$ \\
\hline Maternal age (y) & $29 \pm 5.33$ & $29 \pm 6.72$ \\
\hline Gravidity & $2.8 \pm 1.8$ & $2.8 \pm 1.9$ \\
\hline Parity & $1(0-6)$ & $1(0-9)$ \\
\hline Gestational age (wk) & $38 \pm 1.6$ & $35 \pm 3.8^{a}$ \\
\hline \multicolumn{3}{|l|}{ Mode of delivery } \\
\hline Vaginal & 23 & 67 \\
\hline Cesarean section & 44 & 153 \\
\hline Nulliparity & $18(27 \%)$ & $74(34 \%)$ \\
\hline Newborn weight (g) & $3198 \pm 455$ & $2389 \pm 939.1^{b}$ \\
\hline \multicolumn{3}{|l|}{ Apgar score } \\
\hline $1 \mathrm{~min}$ & $9 \pm 0.3$ & $7.3 \pm 2.2 \mathrm{c}$ \\
\hline $5 \min$ & 10 & $8.5 \pm 1.9^{d}$ \\
\hline \multicolumn{3}{|c|}{ Blood pressure (mmHg) } \\
\hline Systolic & $110 \pm 10.2$ & $141 \pm 17.4^{\mathrm{e}}$ \\
\hline Diastolic & $72 \pm 9.6$ & $91 \pm 13^{f}$ \\
\hline \multicolumn{3}{|l|}{ Proteinuria } \\
\hline No & $58(100 \%)$ & $0^{g}$ \\
\hline+1 & 0 & $53(25 \%)^{\mathrm{h}}$ \\
\hline+2 & 0 & $103(48.5 \%)^{i}$ \\
\hline$+3-+4$ & 0 & $56(26.4 \%)^{\mathrm{j}}$ \\
\hline
\end{tabular}

Data were presented as mean $\pm S D$, median (min-max), and percentage as appropriate. $a, b, c, c, d, e, f, g, h, i, j p<0.05$ vs. controls

Table 2: Hematological analyses of study groups

\begin{tabular}{lc|c}
\hline & $\begin{array}{l}\text { Controls } \\
(\mathrm{n}=58)\end{array}$ & $\begin{array}{l}\text { Preeclampsia } \\
(\mathrm{n}=212)\end{array}$ \\
\hline WBC $\left(1 \times 10^{3} / \mathrm{mcL}\right)$ & $9.5(5.9-22.5)$ & $11.5(1.4-23.2)^{\mathrm{a}}$ \\
Differential $\left(1 \times 10^{3} / \mathrm{mcL}\right)$ & & $9(1.2-21.7)^{\mathrm{b}}$ \\
Neutrophils & $7.1(3.8-13.9)$ & $1.9(0.1-5.0)^{\mathrm{c}}$ \\
Lymphocytes & $1.8(1.0-3.8)$ & $12.9(8.9-17.6)$ \\
Hemoglobin $(\mathrm{g} / \mathrm{dL})$ & $12.3(9.2-16.2)$ & $218.0(46.0-622.0)$ \\
Platelets $\left(1 \times 10^{3} / \mathrm{mcL}\right)$ & $219.0(112.0-432.0)$ & $(19.0)$ \\
\hline
\end{tabular}

WBC: White blood cell. Data were presented as median (min-max). a,b,c $p<0.05$ vs. controls 


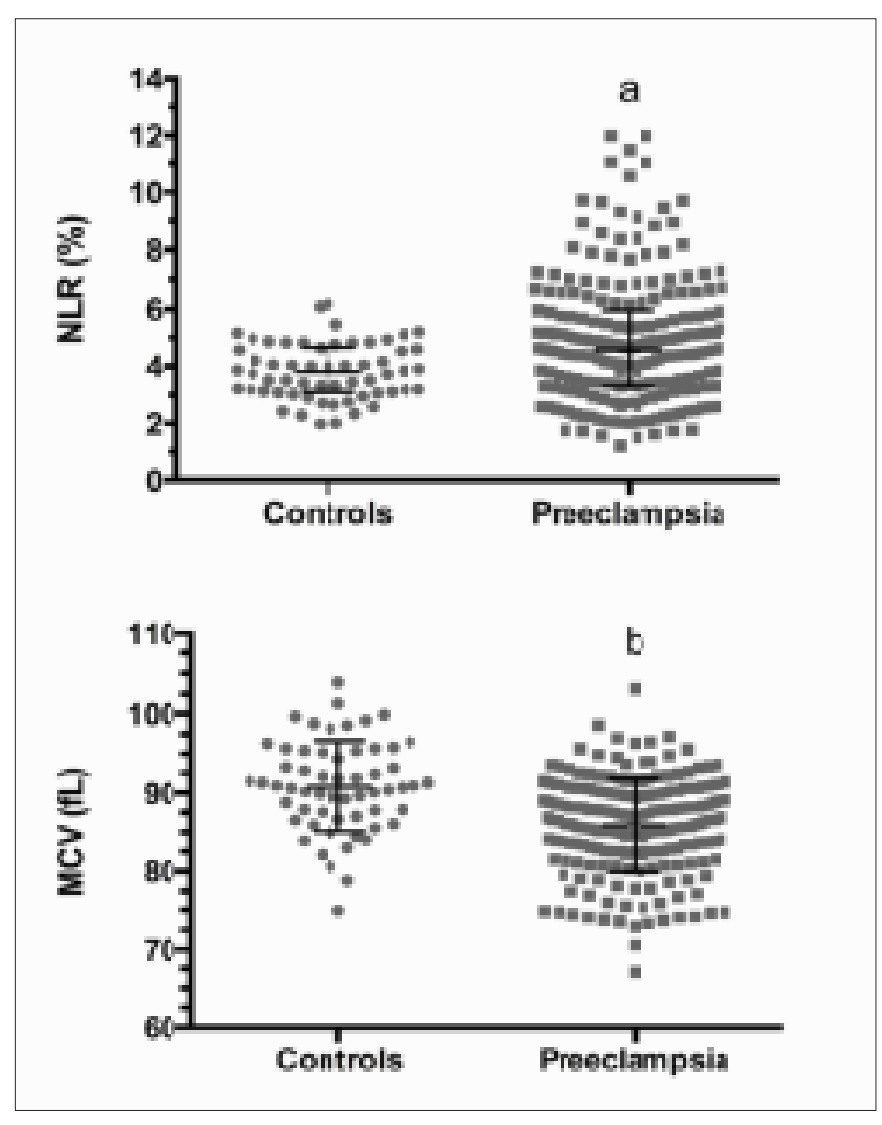

Figure 1: NLR and MCV of the preeclampsia group and controls. NLR, neutrophil to lymphocyte ratio; MCV mean corpuscular volume. For NLR and MCV values, line and whiskers show median and interquartile range, respectively. For MCV values, line and whiskers present mean and standard deviation, respectively. $a, b P<0.05$, preeclamptic pregnancy group vs. controls.

\section{Discussion}

Our study has highlighted the potential importance of NLR as a diagnostic marker for preeclampsia. We found that the WBCs counts, NLR, and MCV were considerably higher in the preeclamptic women. On the other hand, both neutrophil and lymphocyte counts were found to be lower in preeclamptic patients.

Leukocytosis, mainly related to neutrophilia, is a common finding in normal pregnancy. After eight weeks, neutrophilia begins to occur, and neutrophil count stabilizes in the second half of pregnancy. At this time, total WBC counts range from 9,000 to15,000 cells/microliter (5). Absolute lymphocyte counts and relative numbers of $\mathrm{T}$ and $\mathrm{B}$ lymphocytes did not differ between healthy non-pregnant women and women with uncomplicated pregnancies (11). Accordingly, the control group of our study, which was comprised of women with normal pregnancy, had normal counts of WBC, neutrophils and lymphocytes. Excessive inflammation is one of the factors proposed to cause endothelial dysfunction in preeclampsia, and it is highlighted together with angiogenic imbalance theory as the cause of preeclampsia $(9,12)$. Pregnancy itself is characterized by a generalized systemic inflammation (13).
However, Redman et al. (9) suggested that preeclampsia is at the extreme end of a continuous spectrum of increased inflammatory response that is a hallmark of pregnancy. As shown in the current study, WBC counts of the preeclamptic women were higher than those of the women with normal pregnancy, suggesting an increased inflammatory response in preeclampsia. Leukocytes are important components of the immune system, and play important roles in the physiological conditions and pathophysiology of pregnancy-related disorders involving decidua and placenta (14). Activation of neutrophils is present in placental circulation under hypoxic conditions, and may contribute to increased vascular resistance in preeclamptic pregnancies (15). Cadden et al. (16) demonstrated that there were more neutrophil endothelial adhesion and infiltration into intimal space in systemic vasculature; however, lymphocyte infiltration was not significant and lymphocyte count was much lower.

In women not taking iron supplements, mean corpuscular volume $(\mathrm{MCV})$ declines during pregnancy and is approximately 80 to $84 \mathrm{fL}$ in the third trimester (17). However, MCV rises approximately to $4 \mathrm{fL}$ in healthy pregnant women and in those with only mild iron deficiency (18). During pregnancy, monocyte count does not change, and there may be slight reductions in basophil and eosinophil counts (5). The findings of current study were consistent with those reported by Heilmann et al. (19) regarding that MCV is higher in preeclamptic patients than that in women with normal pregnancy.

Recently, it has been well-characterized that systemic inflammation is associated with alterations in the individual components of the circulating white blood cells (WBCs), especially in the form of neutrophilia with a relative lymphocytopenia $(20,21)$. Therefore, neutrophil to lymphocyte ratio (NLR) has been proposed as an easily measurable objective marker of systemic inflammation and a prognostic factor for a variety of diseases, including cancer, cardiovascular and liver diseases, metabolic syndrome, autoinflammatory diseases, and also obstetric pathologies such as endometriosis, primary ovarian insufficiency, gestational trophoblastic disease, and ovarian hyperstimulation syndrome (22-31). To date, conflicting results have been reported regarding the role of NLR in preeclampsia. Recently, a retrospective pilot study conducted by Kurtoglu et al. (32) showed that the NLR is higher in pregnant women with preeclampsia. On the other hand, Yavuzcan et al. (33) reported that although NLR in pregnant women with severe preeclampsia was higher than that of healthy nonpregnant women, it did not differ from that of healthy pregnant women. We found that the NLR was higher in patients with preeclampsia than that of healthy pregnant women. Further studies are required to determine whether NLR is associated with preeclampsia.

It should be noted that although NLR is easy to measure, its utility as a marker of systemic inflammation may be af- 
fected by several conditions such as maternal systemic infections, maternal malignancies, and chronic inflammatory diseases. In conclusion, NLR may be useful as a biomarker in the differential diagnosis of preeclampsia. Large scale prospective studies needed to determine the optimal NLR value and its prognostic significance in the diagnosis of preeclampsia.

\section{References}

1. August P, Sibai BM. Preeclampsia: Clinical features and diagnosis In: UpToDate, Post, TW (Ed), UpToDate, Waltham, MA, 2014.

2. Abalos E, Cuesta C, Grosso AL, Chou D, Say L. Global and regional estimates of preeclampsia and eclampsia: a systematic review. Eur J Obstet Gynecol Reprod Biol 2013;170:1-7.

3. Duley L. The global impact of pre-eclampsia and eclampsia. Semin Perinatol 2009;33:130-7.

4. Szpera-Gozdziewicz A, Breborowicz GH. Endothelial dysfunction in the pathogenesis of pre-eclampsia. Front Biosci 2014;19:734-46.

5. Kenneth AB. Hematologic changes in pregnancy. In: UpToDate, Post, TW (Ed), UpToDate, Waltham, MA, 2014.

6. Redman CW, Sargent IL. Latest advances in understanding preeclampsia. Science 2005;308:1592-4.

7. Germain SJ, Sacks GP, Sooranna SR, Sargent IL, Redman $\mathrm{CW}$. Systemic inflammatory priming in normal pregnancy and preeclampsia: the role of circulating syncytiotrophoblast microparticles. J Immunol 2007;178:5949-56.

8. Canzoneri BJ, Lewis DF, Groome L, Wang Y. Increased neutrophil numbers account for leukocytosis in women with preeclampsia. Am J Perinatol 2009;26:729-32.

9. Redman CW, Sacks GP, Sargent IL. Preeclampsia: an excessive maternal inflammatory response to pregnancy. Am J Obstet Gynecol 1999;180:499-506.

10. Brown MA, Lindheimer MD, de Swiet M, Van Assche A, Moutquin JM. The classification and diagnosis of the hypertensive disorders of pregnancy: statement from the International Society for the Study of Hypertension in Pregnancy (ISSHP). Hypertens Pregnancy 2001;20:9-14.

11. Kühnert M, Strohmeier R, Stegmüller M, Halberstadt E. Changes in lymphocyte subsets during normal pregnancy. Eur J Obstet Gynecol Reprod Biol 1998;76:147-51.

12. Ramma W, Ahmed A. Is inflammation the cause of preeclampsia? Biochem Soc Trans 2011;39:1619-27.

13. Levine RJ, Thadhani R, Qian C, Lam C, Lim KH, Yu KF, et al. Urinary placental growth factor and risk of preeclampsia. JAMA 2005;293:77-85.

14. Laresgoiti-Servitje E. A leading role for the immune system in the pathophysiology of preeclampsia. J Leukoc Biol 2013;94:247-57.
15. Mellembakken JR, Aukrust P, Hestdal K, Ueland T, Abyholm T, Videm V. Chemokines and leukocyte activation in the fetal circulation during preeclampsia. Hypertension 2001;38:394-8.

16. Cadden KA, Walsh SW. Neutrophils, but not lymphocytes or monocytes, infiltrate maternal systemic vasculature in women with preeclampsia. Hypertens Pregnancy 2008; 27:396-405.

17. Whittaker PG, Macphail S, Lind T. Serial hematologic changes and pregnancy outcome. Obstet Gynecol 1996;88:33-9.

18. Haram K, Nilsen ST, Ulvik RJ. Iron supplementation in pregnancy evidence and controversies. Acta Obstet Gynecol Scand 2001;80:683-8.

19. Heilmann L, Rath W, Pollow K. Hemorheological changes in women with severe preeclampsia. Clin Hemorheol Microcirc 2004;31:49-58.

20. Gabay C, Kushner I. Acute-phase proteins and other systemic responses to inflammation. N Engl J Med 1999; 340:448-54.

21. Zahorec R. Ratio of neutrophil to lymphocyte counts rapid and simple parameter of systemic inflammation and stress in critically ill. Bratisl Lek Listy 2001;102:5-14.

22. Guthrie GJ, Charles KA, Roxburgh CS, Horgan PG, McMillan DC, Clarke SJ. The systemic inflammationbased neutrophil-lymphocyte ratio: experience in patients with cancer. Crit Rev Oncol Hematol 2013;88:218-30.

23. Bhat T, Teli S, Rijal J, Bhat H, Raza M, Khoueiry G, et al. Neutrophil to lymphocyte ratio and cardiovascular diseases: a review. Expert Rev Cardiovasc Ther 2013; $11: 55-9$

24. Alkhouri N, Morris-Stiff G, Campbell C, Lopez R, Tamimi TA, Yerian L, et al. Neutrophil to lymphocyte ratio: a new marker for predicting steatohepatitis and fibrosis in patients with nonalcoholic fatty liver disease. Liver Int 2012;32:297-302.

25. Cho S, Cho H, Nam A, Kim HY, Choi YS, Park KH, et al. Neutrophil-to-lymphocyte ratio as an adjunct to CA-125 for the diagnosis of endometriosis. Fertil Steril 2008; 90:2073-9.

26. Buyukkaya E, Karakas MF, Karakas E, Akçay AB, Tanboga IH, Kurt M, et al. Correlation of neutrophil to lymphocyte ratio with the presence and severity of metabolic syndrome. Clin Appl Thromb Hemost 2014; 20:159-63.

27. Ahsen A, Ulu MS, Yuksel S, Demir K, Uysal M, Erdogan $\mathrm{M}$, et al. As a new inflammatory marker for familial Mediterranean fever: neutrophil-to-lymphocyte ratio. Inflammation 2013;36:1357-62.

28. Oehadian A, Suryadinata H, Dewi S, Pramudyo R, Alisjahbana B. The role of neutrophyl lymphocyte count ratio as an inflammatory marker in systemic lupus erythematosus. Acta Med Indones 2013;45:170-4. 
29. Yıldırım G, Tokmak A, Kokanal MK, Sarkaya E, Züngün $\mathrm{C}$, İnal HA, et al. Association between some inflammatory markers and primary ovarian insufficiency. Menopause 2015;22:1000-5.

30. Guzel AI, Kokanali MK, Erkilinc S, Topcu HO, Oz M, Ozgu E, et al. Predictive role of the neutrophil lymphocyte ratio for invasion with gestational trophoblastic disease. Asian Pac J Cancer Prev 2014;15:4203-6.

31. Verit FF, Cetin O, Yildirim O, Keskin S, Yucel O, Yalcinkaya S. Neutrophil to lymphocyte ratio is superior to platelet to lymphocyte ratio as an early predictor of moderate/severe ovarian hyperstimulation syndrome. J Obstet Gynaecol 2014;34:639-43.

32. Kurtoglu E, Kokcu A, Celik H, Tosun M, Malatyalioglu E. May ratio of neutrophil to lymphocyte be useful in predicting the risk of developing preeclampsia? A pilot study. J Matern Fetal Neonatal Med 2015;28:97-9.

33. Yavuzcan A, Cağlar M, Ustün Y, Dilbaz S, Ozdemir I, Yildiz E, et al. Mean platelet volume, neutrophil-lymphocyte ratio and platelet-lymphocyte ratio in severe preeclampsia. Ginekol Pol 2014;85:197-203. 